\title{
DISCUSSION
}

\section{The effect of surface roughness and shear rate during fall-cone calibration}

\author{
MARCELO A. LLANO-SERNA*, LUIS F. CONTRERAS $\dagger$ and BRENDAN C. O'KELLY
}

\section{Contribution by Brendan C. O'Kelly}

In their paper (Llano-Serna \& Contreras, 2020), the authors provide valuable insights into the effects of surface roughness and shear rate during $30^{\circ}, 80 \mathrm{~g}$ fall-cone calibration, investigating a standardised, smooth, polished cone (arithmetical mean roughness $\left(R_{\mathrm{a}}\right)$ value of $0 \cdot 8 \mu \mathrm{m}$, i.e. compliant with ISO 17892-6 (CEN, 2017)) and two rougher cones with $R_{\mathrm{a}}$ values of 1.5 and $4.7 \mu \mathrm{m}$. The authors report that, for the investigated tailing, kaolin and sediment soils, the experimental result presented in Fig. 6 'seems counterintuitive and does not support a generally accepted concept ... the idea of the roughness as an important influencing factor on the cone mechanics' (Llano-Serna \& Contreras, 2020; p. 338) from which they conclude that 'for the scale of the fall-cone test, roughness changes within the scale of variation analysed here $\left(R_{\mathrm{a}}=0.8-4.7 \mu \mathrm{m}\right)$ do not affect the fall-cone penetration considerably' (Llano-Serna \& Contreras, 2020; p. 338). In this submission, the discusser makes two main contributions: (a) presentation of some experimental data in support of the above finding; $(b)$ the significance of natural variation in the rate dependence parameter $(\mu)$ between different fine-grained soils on the determination of the cone factor, $K$.

For the same specimen preparation methods and testing procedures as those described in the paper under discussion, fall-cone and mini-vane shear tests were performed on a commercially available kaolin $\left(w_{1}=59 \cdot 3 \%, w_{\mathrm{p}}=30 \cdot 2 \%\right)$ for the purposes of this submission. Note that the consistency index values of this material (referred to as kaolin 2) are different from those reported for the kaolin investigated by the authors $(90 \%$ and $36 \%$, respectively) (referred to as kaolin 1), although this is not unexpected since these materials were obtained from different sources. For instance, a different kaolin material investigated by Sivakumar et al. (2015) had reported $w_{1}=70 \%$ and $w_{\mathrm{p}}=33 \cdot 8 \%$. Five $30^{\circ}, 80 \mathrm{~g}$ cones were investigated - that is, a smooth polished one (denoted as FC1), compliant with CEN (2017), and four others manufactured using a lathe machine to have repetitive surface patterns of concentric grooves (see Fig. 10 and Table 6). The various surface patterns for the four manufactured cones, FC2-FC5, were created using a Quaduct carbide thread-cutting tool having a $60^{\circ}$ point angle, employing the same depth of cut (amplitude) value of $0 \cdot 10 \mathrm{~mm}$, advancing the tool by the required amount using the top slide, with pitch (frequency) values ranging from 0.10 to $1.00 \mathrm{~mm}$. In the case of cone $\mathrm{FC} 2$, the process

\footnotetext{
* School of Civil Engineering, The University of Queensland, Brisbane, QLD, Australia; also Klohn Crippen Berger, Brisbane, QLD, Australia (Orcid:0000-0002-4395-8636).

$\uparrow$ School of Civil Engineering, The University of Queensland, Brisbane, QLD, Australia.

t Department of Civil, Structural and Environmental Engineering, Trinity College Dublin, Dublin, Ireland

(Orcid:0000-0002-1343-4428).
}

resulted in the tip of the next groove being removed for the smallest $0 \cdot 10 \mathrm{~mm}$ pitch dimension investigated, such that the reduced amplitude $\left(y_{\max }\right)$ of its finished triangle wave pattern profile was calculated as $0.087 \mathrm{~mm}$. For these profiles, the mathematical values of $R_{\mathrm{a}}$ (arithmetical mean deviation perpendicular to the grooves, which is the direction of motion during indentation) were calculated in the range $5 \cdot 1-21 \cdot 7 \mu \mathrm{m}$ - that is, cones FC2-FC5 have greater roughness than the cones investigated by the authors. It is acknowledged that the repetitive surface patterns on the cones FC3-FC5 are not of real interest for fall-cone practices, but as described later, their results demonstrate that the sole use of the $R_{\mathrm{a}}$ parameter for roughness characterisations may not be always reliable. The vane-shear tests were performed in triplicate, with vane blades measuring $25.4 \mathrm{~mm}$ wide and $25.4 \mathrm{~mm}$ deep, and for a shearing angular velocity $(\omega)$ of $12 \% \mathrm{~min}$, following the recommendation from BS 1377-7 (BSI, 1990b).

Figure 11(a) presents for the kaolin 2 material the average cone penetration depth $\left(h_{\mathrm{d}}\right)$ obtained using cones FC1-FC5 at four altered water contents about the liquid limit condition (defined as $h_{\mathrm{d}}=20 \mathrm{~mm}$ for the $30^{\circ}, 80 \mathrm{~g}$ fall-cone set-up according to BSI (1990a)). Also included in this figure are the vane shear strength-water content data, from which the $K$ values presented in Fig. 11(b) were calculated using the Hansbo (1957) fall-cone relationship (equation (6)). For example, considering cone FC1 $\left(R_{\mathrm{a}}=0.8 \mu \mathrm{m}\right)$, kaolin 2 produced a value of $w_{1}=59 \cdot 3 \%$, with the corresponding vane shear strength interpolated as $s_{\mathrm{u}(\mathrm{LL})}=0.81 \mathrm{kPa}$, giving a computed $K$ value of $0 \cdot 413$. In the same manner, $w_{1}=60.9 \%, s_{\mathrm{u}(\mathrm{LL})}=0.78 \mathrm{kPa}$ and $K=0.398$ were computed for cone FC2 $\left(R_{\mathrm{a}}=21.7 \mu \mathrm{m}\right)$ - that is, for the kaolin 2 , the rough cone (FC2) had practically the same $K$ value as the smooth, polished one (only $3.7 \%$ lower), in agreement with the authors' finding, but appeared to extend it for a considerably wider $R_{\mathrm{a}}$ range. Note, for the same $\omega$ value of $12 \%$ min used in testing kaolin 2 , the kaolin 1 material produced an $s_{\mathrm{u}(\mathrm{LL})} \approx 0.52 \mathrm{kPa}$ (Fig. 7), which results in a computed $K$ value of $0 \cdot 27$. As explained earlier, since these kaolin materials had different consistency indices, it would not be unexpected for them to have different strength parameter $(K)$ values.

The authors postulated 'It may be possible that for larger grooves than those depicted in Figs 4 and 5; the roughness effect is substantial' (Llano-Serna \& Contreras, 2020; p. 338). It is evident from the results presented for the kaolin 2 material in Fig. 11 that the larger $(0 \cdot 10 \mathrm{~mm}$ deep) grooves of the repeating surface patterns for cones FC3-FC5 produced higher values of $w_{1}=62 \cdot 6-63 \cdot 6 \%$ and lower $s_{\mathrm{u}(\mathrm{LL})}=0.72-0.74 \mathrm{kPa}$ compared to cones FC1 and FC2, supporting the authors' hypothesis. According to the theory and experimental observations, rougher cones have lower values of $K$ for a given cone geometry (e.g. Koumoto \& Houlsby (2001)). As is evident from Fig. 11(b), however, compared to cone FC2 $\left(R_{\mathrm{a}}=21 \cdot 7 \mu \mathrm{m}\right.$ and $\left.K=0.398\right)$, the computed $K$ values for cones FC3-FC5 ranged from 0.367 to 


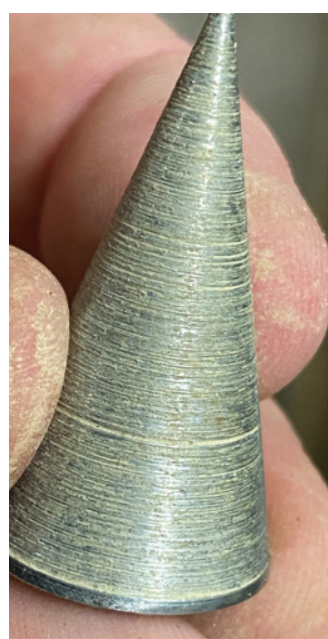

(a)

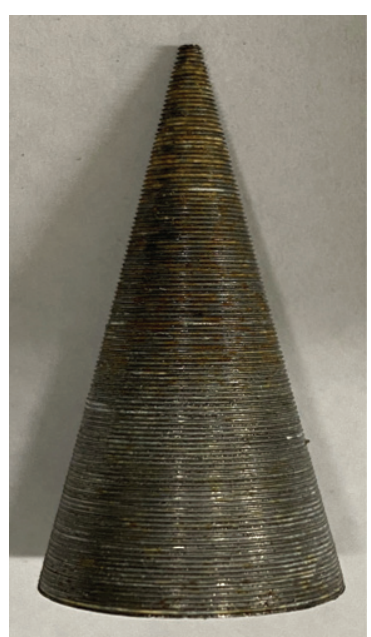

(b)

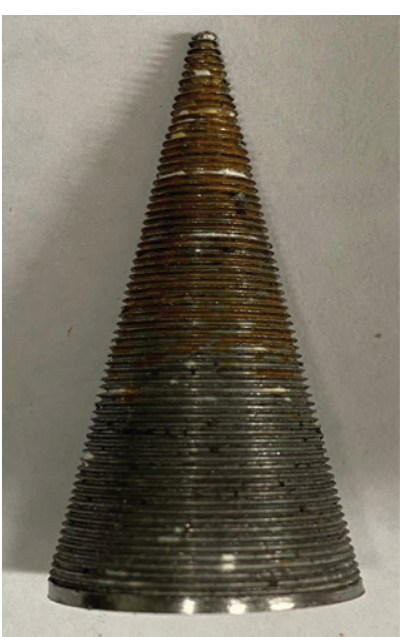

(c)

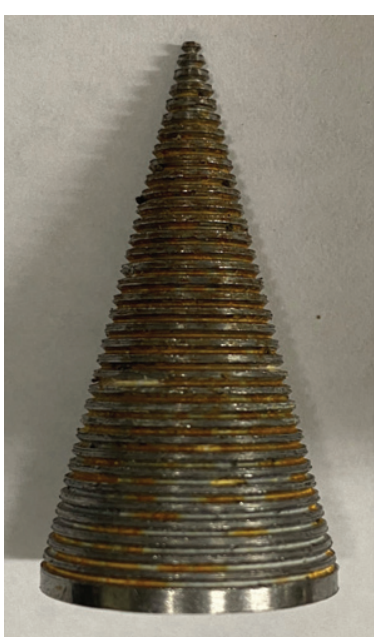

(d)

Fig. 10. Manufactured $30^{\circ}, 80$ g fall cones: (a) FC2; (b) FC3; (c) FC4; (d) FC5

$0 \cdot 377$ (i.e. $5 \cdot 1-7 \cdot 7 \%$ lower) and, furthermore, exhibited a trend of marginally increasing $K$ for increasing $R_{\mathrm{a}}$. The latter phenomenon appears counterintuitive and inconsistent with fall-cone theory, but arise from the sole use of the $R_{\mathrm{a}}$ parameter for roughness characterisations, which is not always reliable. A combination of two roughness parameters is often recommended in surface metrology practice - that is, one related to amplitude and the other to frequency. For instance, compared to FC2 $(21.7 \mu \mathrm{m})$, the cones FC3-FC5

Table 6. Manufactured $30^{\circ}, 80 \mathrm{~g}$ fall cones with various surface patterns and roughness values investigated for the kaolin 2 material $\left(w_{1}=59 \cdot 3 \%, w_{\mathrm{p}}=30 \cdot 2 \%\right)$

\begin{tabular}{l|c|c|c}
\hline Fall cone ID & Depth of cut, $y_{\max }: \mathrm{mm}$ & Pitch: $\mathrm{mm}$ & $R_{\mathrm{a}}: \mu \mathrm{m}$ \\
\hline FC2 & $0 \cdot 087$ & $0 \cdot 10$ & $21 \cdot 7$ \\
FC3 & $0 \cdot 10$ & $0 \cdot 30$ & $11 \cdot 8$ \\
FC4 & $0 \cdot 10$ & $0 \cdot 50$ & $8 \cdot 9$ \\
FC5 & $0 \cdot 10$ & $1 \cdot 00$ & $5 \cdot 1$ \\
\hline
\end{tabular}

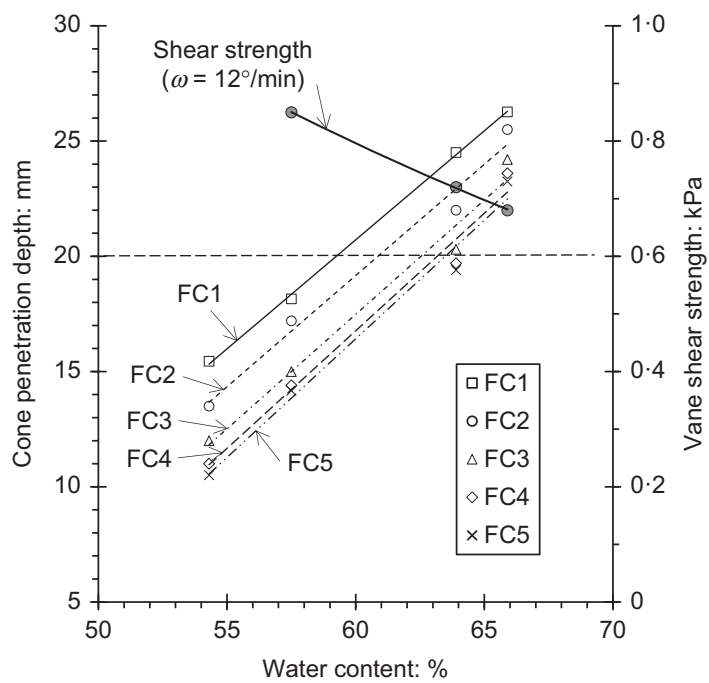

(a) have lower values of $R_{\mathrm{a}}=5 \cdot 1-11 \cdot 8 \mu \mathrm{m}$, since although their grooves are deeper, they are also less frequent.

The second contribution point of this submission concerns the significance of natural variation in the $\mu$ parameter (variation in undrained shear strength, $s_{\mathrm{u}}$, per tenfold increase in strain rate) between different fine-grained soils in relation to the experimental $K$ value. Equation (5) shows a $\mu$ value of $0 \cdot 1$, typically associated with inorganic finegrained soils. However, it is not uncommon for the rate of $s_{\mathrm{u}}$ increase to range between 0.05 and $0 \cdot 15$ (Ladd \& Foott, 1974), and highly organic soils can have even greater $\mu$ values. For instance, the natural water-treatment residue (WTR) material fall-cone tested in accordance with the British standard by O'Kelly (2014), data for which is included in the Bayesian statistical approach analysis presented by the authors, had a measured $\mu$ value of $0 \cdot 20$ (O'Kelly, 2018). Further, in equation (2), $\zeta\left(s_{\mathrm{u}} / s_{\mathrm{ud}}\right)$ indicates the changes in $K$ induced by the rate of strain during cone penetration, with the tailing, kaolin 1 and sediment materials investigated by the authors noted to have a rather considerable variability in $\zeta$ (Figs 6(b)-6(d)), with reported mean $\zeta$ values of $0 \cdot 48,0.53$ 


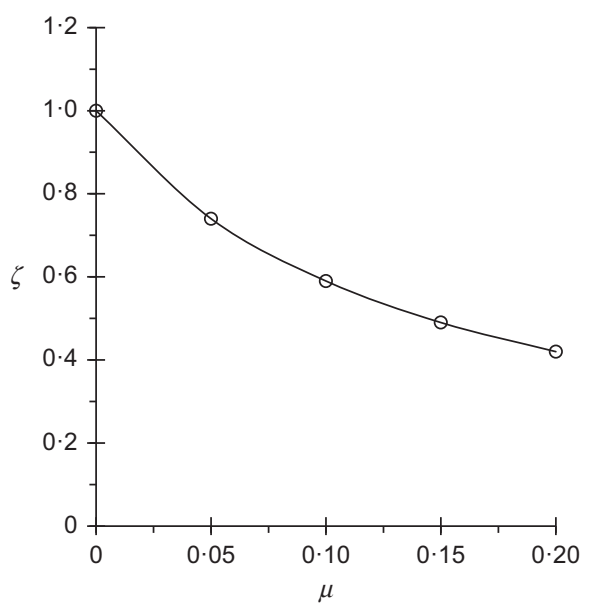

Fig. 12. Plot of $\zeta\left(s_{\mathrm{u}} / s_{\mathrm{ud}}\right)$ against the rate dependence parameter determined from numerical analysis of the fall-cone test $\left(30^{\circ}\right.$ cone $)$ by Hazell (2008)

and $0 \cdot 43$, respectively. As such, according to the correlation given in Fig. 12, these soils could have markedly different $\mu$ values. The authors state that 'the resulting $K$ using equation (6) and adopting different types of soils and several $\omega$ values should follow a linear trend in a semi-log plot similar to the one described by equation (5)" (Llano-Serna \& Contreras, 2020; p. 334), from which they introduce equation (7) used to interpret the calibration data supporting their work, arguing that 'similarly to equation (5) ..., equation (7) should present a constant increase defined by $K S \ldots$ and is valid for more than one soil type' (Llano-Serna \& Contreras, 2020; p. 334). The authors seem to be implying that best-fit linear trendlines to the data points for each of the kaolin 1, WTR and other soils investigated would be coincident in the semi-log plot. However, since these materials have considerably different experimental $\zeta(\mu)$ parameter values, it is suggested that this would not be the case.

As a minor correction to the original paper, the citations to O'Kelly (2016) and O'Kelly et al. (2017) listed their wrong publication years - the correct references (O'Kelly, 2018; O'Kelly et al., 2018) are included in the References section below.

\section{ACKNOWLEDGEMENTS}

The rough cones investigated were manufactured by Mr David Mc Aulay and the experimental testing was performed by Mr Pius Agwaze in the Department of Civil, Structural and Environmental Engineering, Trinity College Dublin. Their contributions are greatly appreciated.

\section{NOTATION}

$h_{\mathrm{d}}$ cone penetration depth

$K$ cone factor

$K I$ empirical model intercept

$K S$ empirical model slope

$R_{\mathrm{a}} \quad$ surface roughness

$s_{\mathrm{u}} \quad$ undrained shear strength

$s_{\text {ud }}$ dynamic undrained shear strength

$s_{\mathrm{u}(\mathrm{LL})} \quad$ vane shear strength at fall-cone liquid limit

$w_{1}$ liquid limit

$w_{\mathrm{p}}$ plastic limit

$\zeta$ ratio of static undrained strength to dynamic undrained strength

$\mu$ rate dependence parameter

$\omega$ shearing angular velocity

\section{REFERENCES}

BSI (1990a). BS 1377-2: Methods of test for soils for civil engineering purposes - Part 2: Classification tests. London, UK: BSI.

BSI (1990b). BS 1377-7: Methods of test for soils for civil engineering purposes - Part 7: Shear strength tests (total stress). London, UK: BSI.

CEN (European Committee for Standardization) (2017). EN ISO 17892-6: Geotechnical investigation and testing - laboratory testing of soil - Part 6: Fall cone test. Brussels, Belgium: CEN.

Hansbo, S. (1957). A new approach to the determination of the shear strength of clay by the fall cone test. Proc. R. Swed. Geotech. Inst. 14, 1-48.

Hazell, E. (2008). Numerical and experimental studies of shallow cone penetration in clay. DPhil thesis, University of Oxford, Oxford, UK.

Koumoto, T. \& Houlsby, G. T. (2001). Theory and practice of the fall cone test. Géotechnique 51, No. 8, 701-712, https://doi.org/ 10.1680/geot.2001.51.8.701.

Ladd, C. C. \& Foott, R. (1974). New design procedure for stability of soft clays. J. Geotech. Engng Div., ASCE 100, No. 7, 763-786.

Llano-Serna, M. A. \& Contreras, L. F. (2020). The effect of surface roughness and shear rate during fall-cone calibration. Géotechnique 70, No. 4, 332-342, https://doi.org/10.1680/jgeot. 18.P.222.

O'Kelly, B. C. (2014). Characterisation and undrained strength of amorphous clay. Proc. Instn Civ. Engrs - Geotech. Engng 167, No. 3, 311-320, https://doi.org/10.1680/geng.11.00025.

O'Kelly, B. C. (2018). Fall-cone strength testing of municipal sludges and residues. Environ. Geotech. 5, No. 1, 18-30, https://doi.org/ 10.1680/jenge. 15.00080 .

O'Kelly, B. C., Vardanega, P. J. \& Haigh, S. K. (2018). Use of fall cones to determine Atterberg limits: a review. Géotechnique 68, No. 10, 843-856, https://doi.org/10.1680/jgeot.17.R.039.

Sivakumar, V., O’Kelly, B. C., Henderson, L., Moorhead, C. \& Chow, S. H. (2015). Measuring the plastic limit of fine soils: an experimental study. Proc. Instn Civ. Engrs - Geotech. Engng 168, No. 1, 53-64, https://doi.org/10.1680/geng.14.00004. 